\title{
Innovation Ability Cultivation of College Students in Scientific Research
}

\author{
Z.Y.PENG \\ School of Physical Education, Shanxi Datong University, Datong City, Shanxi Province, 037009, China
}

H.M. LIU*

School of Physical Science and Electronic, Shanxi Datong University, Datong, Shanxi 037009, China

\begin{abstract}
According to university education status quo of weak social innovation, combined with college students thinking ability and knowledge, proposed financing social innovation in everyday teaching philosophy, mainly through everyday teaching continue to integrate into innovative ideas, research and innovation to create atmosphere, attention to mentoring, development students research echelon of these methods to enhance students' cognitive, while opening up the students' innovative thinking to improve the students' scientific literacy innovation.
\end{abstract}

KEYWORD: In order to; MS Word

\section{INTRODUCTION}

As the core vitality of a nation, the innovation is the most important content included in the university education currently, hence besides studies of the relevant expertise, the development the professional diathesis and innovation ability of students through the teaching mode, the innovation of the educational philosophy are included in the university education. From the thought development of college students and knowledge level of, they have the possibility and feasibility to engage in the innovative activities, and they are also exercised by the school through a number of methods and means for their innovative ability. Now, the college educations mainly focus on the self-innovation of the students, which is confined to "self-creation" in a classroom situation, furthermore the social significance of the innovation of -*the college students is ignored. Hence, the innovation of the students aren't combined with the practical applications and advanced technology due to the lack of the exercise in the social science innovation, which will result in the unbalanced relationship between the society requirements of the creative spirit and innovation capacity after graduating and the ability of the students. In response to this wides pread problem in university education, some operations can be done to enhance the social innovation ability of students and to improve the intrinsic innovation mechanisms and the attainments of the students in the scientific researches.

\section{METHODS}

\subsection{Innovative ideas continually into the daily teaching}

University education is the transition of the students from the school to the community, and it lays a solid foundation for the follow-up social work of the students, and thus the innovation pursued by the university education should be the unity of self and society, and the transition from the self-creation and the social-creation should be paid attention in the university education. In the college, the knowledge of the students is achieved through theoretical teaching and practical teaching, which mphasizes the self-innovation of the students. In order to further strengthen the cultivation of the social innovation, the theoretical knowledge in the textbooks and practical application should be combined in the teaching to show the relationship between these knowledge and the existing technology. In addition, it is also combined with the cutting-edge of scientific development to expand students" ability, and further point out that the status, the prospects, and the developments of this technique and the unresolved problems now. As a result. Not only the purpose is releasized to stimulate classroom atmosphere and enthusiasm for learning, at the same time, these operations fully mobilize the enthusiasm of students to explore new knowledge and new technology, and gradually establish a scientific innovative ideas and the perseverance spirit of science of the students. In addition, teachers can also carry out a number of lectures on the latest relevant innovative products 
and technologies, which can expand students' professional knowledge, furthermore make students realize the importance of the innovation in the process in the social development. In the practice teaching, it is combined with the existing level of knowledge of students by the existing teaching conditions that the teacher can develop several innovative topics for the students to experience and participate in the innovation activities. In a word, these operations not only exercise the abilities of the students to use knowledge and to practice, but also develop students' creative thinking to finish the change from the initial mimic the behavior to the independent innovation.

\subsection{Encourage the innovation, and create the atmosphere of the research and the innovation}

Based on the characteristics of the university education, in the college, the thought of the students are developed from the primary dialectical thinking gradually to the dialectical thinking which have a very important position in general engineering technical personnel and the knowledge of students is improved from the initial theory gradually to the level of expertise mastered by the related professional and technical personnels, which not only shows that the students have the intelligence basis used to think creatively, but also has the basic skills engaging in innovative activities. Hence, the university education not only let the students to learn the professional knowledge, but also encourage the students to do the research innovation activities as the outward expansion. For example, the University can open laboratory to students, encourage students to participate Electronic Design Contest, encourage students to participate in the research and innovation activities, and the use of scoring policies and incentives of the research to provide with a solid foundation and policy support for the carrying out a wide range of extracurricular activities in science and technology innovation.In addition, according to the characteristics of professional courses, the teaching in the classroom may combined with practical application by introducing technological innovation in the actual production to make the students understand the promotion to social development from the transformation of the knowledge and innovation. For example, information optics is a new interdisciplinary subject, and its corresponding technologies are being or have been applied into practice. In its teaching, a teacher can inserted in the introduction of these new technologies, lead students to use their spare time to visit some of the relevant company's production line, invite the engineers to explain the implementation process of these technologies, furthermore note the difference between this new technology with the existing technology etc. These operations above can allow students to experience and participate in practical applications, and thus the knowledge of the students is enhanced. More importantly, they can make the students to recognize the promotion to development of social productivity effect from the scientific innovation, and stimulate the enthusiasm of students to participate in the research and innovation activities. Besides, the university can also promote the importance of scientific innovation through science and cultural activities and other ways. In short, whether it is through the school's policy support, or through a combination of practical application, we mobilize students to engage in research activities in science and technology innovation initiative, at the same time. we must also strive to create a good scientific research innovation environment with knowledge, so that students can gradually moving from watch of the research to the love of research, which will establish the position of the science and technology activities of the students in the university teaching.

\subsection{Pay attention to the tutor system to develop research groups of the students}

In the college, the research activities is an essential method to develop the creative potential of the students. The students only can understand what is the scientific research by participating in the innovative activities of the scientific research to stimulate their inherent ability of the scientific research and to improve their basic the structure of the research capabilities. As we all known, the usual study of the students is mainly based on that of the basic theory and the general experimental operation in the university. If they want to engage in independent research and innovation activities, the difficulty will be relatively large, and this difficulty may result in the stop of the students in the creative activities. For this case, the tutorial system can be implemented in the university education which builds a good communication bridge between the teachers and the students. When the students get into trouble in the process of the scientific research and the innovation in practice, the teacher can help students to solve these problems encountered and point out the causes and the possible solutions of these problem. As a result, the students can gradually achieve the capabilities of the research and the innovation through the long-term ideas exchange between the instructors and the students. For a given research topic, the students can collect data, filter data, select the appropriate research programs, and write papers, etc with the help of the tutors, and they can independently carry out a preliminary study and the innovation. In addition, the research teams which are based on the third and fourth grade students and supplemented by the first and second grade students are also set up, and they are done by supervisor 
responsibility system. For some great potential research topics and the tackle problems in the technologies, the spare time of the students is taken full advantage of to participate in research activities stimulated by the use of the mutual help in a team, the competitive incentives bettween the different team, and scientific research lectures to cultivate the interest of the scientific research. As a result, the ability of students to carry out innovative work is improved which will provide with the foundation for the subsequent innovative work in related industries.

\section{CONCLUSIONS}

In summary, in order to enhance the social innovation ability of the college Students, university education should adopt the following methods. Firstly, concept of the social sciences innovation activities should added into the everyday theoritical teaching and the practice teaching to foster the innovative ideas of the students; secondly, the atmosphere of the scientific research is built by encouraging the students to conduct scientific research and the innovation based on the operations such as conducting lectures and he implementation of research grading; finally, the students groups based on the scientific research is developed by the participation of the students in scientific innovation activities students and the establish of the Tutorial System. These methods above can develop students' science and technology innovation literacy, and it not only can increase of the understanding in the professional knowledge, but can also improve the scientific innovation to meet the innovative work of the students in the future.

\section{ACKNOWLEDGMENTS}

The work was supported by Launching Scientific Research Funds for Doctors (Grant NO. 2012-B-04).

\section{REFERENCES}

[1] Huang C. 2010. The Status and Countermeasures of Medical Students' Ability in Scientific Research Creation. Journal of Liaoning Medical University (Social Science Edition), 8(2): 28-31.

[2] Luo H., Zhang W., Jiang G., Han C. 2013. Research and innovation capability training of college student depending on national key disciplines Preliminary agronomy teaching, Teaching Forum, 10: 179-180.

[3] Chen Z, Shan Y., Chu J.,2013. Cultivation Countermeasures of college Scientific Research Innovative Ability of Student with a body of undergraduate and master. Culture, 8: 173175.

[4] Bai X., Zhang Y., Liang T. 2002. To Combine Study with the Scientific Research and Improve the Innovative Quality of Undergraduates. Journal of Hebei University of Science and Technology ( Social Sciences), 2 (2) :72-75.

[5] Lu H., Liang L., Gong Y., Wang K.. 2011. Training computer professional creative talents with research and innovation activities of college as a carrier. China University Teaching. 3: 34-36.

[6] Huang S., Li R., Pan Q., Huang S.2011.Study and Practice of Training Scientific Research Ability of College Students in Undergraduate Tutorial System. Higher Education Forum, 2:22-24. 